\title{
JPN Guidelines for the management of acute pancreatitis: surgical management
}

\author{
Shuji Isaji ${ }^{1}$, Tadahiro Takada ${ }^{2, *}$, Yoshifumi Kawarada ${ }^{3}$, Koichi Hirata ${ }^{4}$, Toshihiko Mayumi ${ }^{5}$, \\ Masahiro Yoshida ${ }^{2}$, Mino Sekimoto $^{6}$, Masahiko Hirota $^{7}$, Yasutoshi Kimura ${ }^{4}$, Kazunori Takeda ${ }^{8}$, \\ Masaru Koizumi ${ }^{9}$, Makoto Otsuki $^{10, * *}$, and Seiki Matsuno ${ }^{11, * * *}$ \\ ${ }^{1}$ Department of Hepatobiliary Pancreatic Surgery and Breast Surgery, Mie University Graduate School of Medicine, 2-174 Edobashi, Tsu, \\ Mie 514-8507, Japan \\ ${ }^{2}$ Department of Surgery, Teikyo University School of Medicine, Tokyo, Japan \\ ${ }^{3}$ Ueno Municipal Hospital, Mie, Japan \\ ${ }^{4}$ First Department of Surgery, Sapporo Medical University School of Medicine, Hokkaido, Japan \\ ${ }^{5}$ Department of Emergency and Critical Care Medicine, Nagoya University Graduate School of Medicine, Nagoya, Japan \\ ${ }^{6}$ Department of Healthcare Economics and Quality Management, Kyoto University Graduate School of Medicine, Kyoto, Japan \\ ${ }^{7}$ Department of Gastroenterological Surgery, Kumamoto University Graduate School of Medical Science, Kumamoto, Japan \\ ${ }^{8}$ Department of Surgery, National Hospital Organization Sendai Medical Center, Sendai, Japan \\ ${ }^{9}$ Ohara Medical Center Hospital, Fukushima, Japan \\ ${ }^{10}$ Department of Gastroenterology and Metabolism, University of Occupational and Environmental Health, Japan, School of Medicine, \\ Kitakyushu, Japan \\ ${ }^{11}$ Division of Gastroenterological Surgery, Tohoku University Graduate School of Medicine, Sendai, Japan
}

\begin{abstract}
Acute pancreatitis represents a spectrum of disease ranging from a mild, self-limited course to a rapidly progressive, severe illness. The mortality rate of severe acute pancreatitis exceeds $20 \%$, and some patients diagnosed as mild to moderate acute pancreatitis at the onset of the disease may progress to a severe, life-threatening illness within 2-3 days. The Japanese (JPN) guidelines were designed to provide recommendations regarding the management of acute pancreatitis in patients having a diversity of clinical characteristics. This article sets forth the JPN guidelines for the surgical management of acute pancreatitis, excluding gallstone pancreatitis, by incorporating the latest evidence for the surgical management of severe pancreatitis in the Japanese-language version of the evidence-based Guidelines for the Management of Acute Pancreatitis published in 2003. Ten guidelines are proposed: (1) computed tomography-guided or ultrasound-guided fineneedle aspiration for bacteriology should be performed in patients suspected of having infected pancreatic necrosis; (2) infected pancreatic necrosis accompanied by signs of sepsis is an indication for surgical intervention; (3) patients with sterile pancreatic necrosis should be managed conservatively, and
\end{abstract}

Offprint requests to: $\mathrm{S}$. Isaji

* President, Japanese Society of Emergency Abdominal Medicine; President, Japanese Society of HepatoBiliary-Pancreatic Surgery; President, Asian-Pacific Hepato-Pancreato-Biliary Association

** Chairman, Intractable Pancreatic Disease Investigation and Research Group of the Japanese Ministry of Health, Labour and Welfare

*** President, Japan Pancreas Society surgical intervention should be performed only in selected cases, such as those with persistent organ complications or severe clinical deterioration despite maximum intensive care; (4) early surgical intervention is not recommended for necrotizing pancreatitis; (5) necrosectomy is recommended as the surgical procedure for infected pancreatic necrosis; (6) simple drainage should be avoided after necrosectomy, and either continuous closed lavage or open drainage should be performed; (7) surgical or percutaneous drainage should be performed for pancreatic abscess; (8) pancreatic abscesses for which clinical findings are not improved by percutaneous drainage should be subjected to surgical drainage immediately; (9) pancreatic pseudocysts that produce symptoms and complications or the diameter of which increases should be drained percutaneously or endoscopically; and (10) pancreatic pseudocysts that do not tend to improve in response to percutaneous drainage or endoscopic drainage should be managed surgically.

Key words Necrotizing pancreatitis - Infected pancreatic necrosis - Sterile pancreatic necrosis - Pancreatic abscess Pancreatic pseudocyst

\section{Clinical questions}

CQ1. Which procedure will best result in a definite diagnosis of infected pancreatic necrosis?

CQ2. What is the indication for surgical intervention in necrotizing pancreatitis?

CQ3. How should sterile pancreatic necrosis be managed? 
CQ4. What is the optimal timing for surgical intervention?

CQ5. What is the optimal surgical procedure for infected pancreatic necrosis?

CQ6. What is the optimal drainage procedure after necrosectomy?

CQ7. How should pancreatic abscess be managed?

CQ8. What is the indication for surgical drainage in pancreatic abscess?

CQ9. What are the indications for drainage treatment in pancreatic pseudocysts?

CQ10. What is the indication for surgical intervention in pancreatic pseudocysts?

\section{Introduction}

Research on the pathophysiology of acute pancreatitis has progressed dramatically during the past 20 years. As the number of randomized controlled studies (RCTs, mainly done in the United States and Europe) on the management of severe acute pancreatitis has increased, evidence-based management has come to be demanded. Several guidelines and recommendations for acute pancreatitis have been published in recent years, ${ }^{1-4}$ and three institutions in Japan - the Japanese Society for Abdominal Emergency Medicine, the Japan Pancreas Society, and the Research Group for Intractable Diseases and Refractory Pancreatic Diseases, which is sponsored by the Japanese Ministry of Health, Labour and Welfare - collaborated to publish the Japanese-language version of the evidence-based Guidelines for the Management of Acute Pancreatitis in 2003. This paper sets forth the JPN guidelines for the surgical management of acute pancreatitis, which incorporate the latest evidence for the surgical management of severe pancreatitis and are based on the Japaneselanguage version of the guidelines. The surgical management of gallstone pancreatitis is included in the JPN guidelines for the treatment of gallstone-associated acute pancreatitis.

\section{Clinical course of acute pancreatitis}

The majority of acute pancreatitis cases (around 80\%) are mild and self-limiting, and the patients spontaneously recover within 4-5 days after onset. Mild cases have a mortality rate of $1 \%$ or less and rarely require intensive care or surgical management. ${ }^{1}$

However, severe acute pancreatitis develops in $10 \%-$ $20 \%$ of cases and part of the pancreas and surrounding tissue becomes necrotic. Severe cases are associated with local complications such as major organ failure, pancreatic necrosis, pancreatic abscess, and pancreatic pseudocysts and are generally classified into two stages. ${ }^{5}$ The first stage of severe acute pancreatitis, the period within 2 weeks after the onset of the disease, is characterized by the systemic inflammatory response syndrome (SIRS), and pancreatic necrosis develops in parallel with that within the first 4 days after onset. The second stage begins 2 or 3 weeks after onset with the development of infectious pancreatic complications such as infected pancreatic necrosis (bacterial infection of the pancreatic necrosis) and pancreatic abscess. Infection of pancreatic necrosis is a major prognostic risk factor in severe pancreatitis, and sepsis-related multiple organ failure is the main life-threatening complication with a mortality rate of $20 \%-50 \%$.

\section{Necrotizing pancreatitis}

Clinical Question (CQ) 1. Which procedure will best result in a definite diagnosis of infected pancreatic necrosis?

Computed tomography (CT)-guided or ultrasound (US)-guided fine-needle aspiration for bacteriology should be performed in patients suspected of having infected pancreatic necrosis (Recommendation A)

Acute pancreatitis is classified morphologically into edematous pancreatitis and necrotizing pancreatitis. Edematous pancreatitis accounts for $80 \%-85 \%$ of cases of acute pancreatitis, and most of them are self-limiting and do not require special treatment. The mortality rate for necrotizing pancreatitis, which accounts for $15 \%-$ $20 \%$ of cases, is $30 \%-40 \% .{ }^{6}$ The mortality rate for infected pancreatic necrosis is high $-40 \%$ on average, ${ }^{7}$ and some studies report rates of more than $70 \% .{ }^{8}$ In contrast, the mortality rate of sterile pancreatic necrosis with no bacterial infection has been reported as being $0 \%-11 \% .{ }^{9,10}$

Findings suggest that infected pancreatic necrosis presents with a worsening of clinical manifestations and hematological data, a blood culture with positive bacterial results, and a positive result on the endotoxin test of blood and gas in and around the pancreas on a CT scan. However, these findings are merely indirect evidence of infection in general. CT- or US-guided fine-needle aspiration for bacteriology of pancreatic or peripancreatic necrosis has been established as an accurate, safe, and reliable technique for identifying infected necrosis. Its accuracy is high, at $89.4 \%-100 \%$ (Level $2 b),{ }^{11,12}$ and it is safe if the correct puncture route is chosen and complications such as intestinal injury do not result (Level 2b). 
Indications for surgery

CQ2. What is the indication for surgical intervention in necrotizing pancreatitis?

Infected pancreatic necrosis accompanied by signs of sepsis is an indication for surgical intervention (Recommendation B)

It is generally agreed that necrotizing pancreatitis with proven infected necrosis is an indication for surgical intervention (Level 5) ${ }^{1,13,14}$ It is rarely managed conservatively without surgical intervention.

CQ3. How should sterile pancreatic necrosis be managed?

Patients with sterile pancreatic necrosis should be managed conservatively and undergo surgical intervention only in selected cases, such as those with persistent organ complications or severe clinical deterioration despite maximum intensive care (Recommendation B)

Whether sterile pancreatic necrosis is an indication for surgical intervention remains a matter of controversy. Patients often recover from sterile pancreatic necrosis in response to conservative nonsurgical management (Levels 2c-3b). ${ }^{9,15-17}$ However, many reports state that failure of acute pancreatitis to improve in response to optimal therapy in an intensive care unit should be an indication for surgical intervention, irrespective of whether the patient has an infection (Levels 2c-3b)..$^{18-22}$ However, these reports have differing views about the length of time that conservative management should be applied before surgical intervention is considered, with the period ranging from 3-5 days to more than 5 weeks. A review ${ }^{23}$ examining this issue has indicated that although it is difficult to recommend an exact duration, at least 3-4 weeks of conservative management is desirable. However, there are no comparative studies to justify such a conclusion.

\section{Timing of surgery}

CQ4. What is the optimal timing for surgical intervention?

Unless there are specific indications, early surgery is not recommended for necrotizing pancreatitis (Recommendation D)

In the past, early surgical intervention was recommended for severe acute pancreatitis, which is often accompanied by major organ failure, beginning in the early stage after onset. However, the high mortality rate of up to $65 \%$ casts doubt on the benefits of early surgical intervention.
A retrospective study on the timing of surgery for severe pancreatitis ${ }^{24}$ revealed a mortality rate in patients treated by delayed surgery of $12 \%$, which is significantly lower than the $39 \%$ rate for those who underwent early surgery; thus, surgical intervention should be delayed as long as possible in severe pancreatitis. The only $\mathrm{RCT}^{25}$ comparing early surgery (pancreatic resection/debridement within $72 \mathrm{~h}$ of onset) and delayed surgery (the same procedure 11 days after onset) yielded mortality rates of $56 \%$ and $27 \%$, respectively. Although the difference between the rates was significant, the trial was terminated because of the very high mortality rate for the patients who underwent early surgery.

The above findings indicate that surgical intervention (necrosectomy) for severe acute pancreatitis patients should be deferred as long as possible (3-4 weeks after the onset). ${ }^{1,3}$ The reason for this is that the border between normal and necrotic pancreatic tissue becomes more distinct with time, and this may minimize intraoperative hemorrhage and avoid unnecessary removal of normal pancreas. However, a questionnaire survey of physicians specializing in hepatobiliary pancreatic diseases in Europe that asked about surgical intervention for severe pancreatitis showed no consensus regarding the timing of surgery. ${ }^{26}$

\section{Surgical procedures}

CQ5. What is the optimal surgical procedure for infected pancreatic necrosis?

Necrosectomy is recommended as the optimal surgical procedure for infected pancreatic necrosis (Recommendation A)

Surgical procedures employed to treat severe acute pancreatitis in the past included mobilization and drainage of the pancreatic bed and extended pancreatic resection. Drainage of the pancreatic bed was widely used in Japan as a standard surgical procedure in the 1980s through the early 1990s. However, it is no longer used because maximal therapy in an intensive care unit has become the principal procedure for managing severe acute pancreatitis and the advances in imaging modalities have provided objective evidence that the necrotic tissue cannot be removed by a simple drainage procedure.

On the other hand, the extended pancreatic resection that was the major procedure used mainly in European countries from the 1970s through the 1980s has been increasingly avoided in view of the high incidence of postoperative complications, the failure to improve the overall life-saving rate (Level $1 b-3 b),{ }^{27,28}$ and the lowered quality of life in surviving patients because of the development of abnormal glucose tolerance. ${ }^{27}$

Necrosectomy, or debridement of necrotic tissue, including necrotic pancreatic tissue and peripancreatic fat 
necrosis, is currently used as the key procedure for necrotizing pancreatitis, and no other surgical procedure produces a better outcome (Level 2c)..$^{21,29}$

\section{Drainage procedures after necrosectomy}

CQ6. What is the optimal drainage procedure after necrosectomy?

Simple drainage (Recommendation D) should be avoided as the drainage procedure after necrosectomy, and either continuous closed lavage or open drainage (planned necrosectomy) (Recommendation B) should be performed instead. The choice between these two procedures can be made at the time based on the surgical findings and/or surgeon's experience

Necrosectomy for necrotizing pancreatitis is designed to remove as much necrotic pancreatic tissue as possible. However, because complete debridement is difficult as a result of hemorrhage and because the outcome depends on how thoroughly the remaining necrotic tissue is removed, ${ }^{29}$ the simple (conventional) drainage performed in the past should be avoided.

The drainage procedures used to remove the necrotic foci after necrosectomy can be mainly classified as (1) conventional drainage, (2) continuous closed lavage, and (3) open drainage. Conventional drainage is simple drainage through an indwelling drainage tube. Continuous closed lavage consists of continuous local irrigation with 6-81/day physiological saline through an indwelling double-lumen tube and is continued until no discharge of necrotic tissue is observed ${ }^{21}$ Open drainage is direct drainage through the open wound in the abdominal wall achieved by packing the retroperitoneal space and lesser sac with gauze after necrosectomy, and the same procedure is repeated as scheduled (every 2-3 days) until necrotic tissue is no longer observed. ${ }^{29}$

Discussion of the comparative advantages of various drainage procedures has continued for more than 20 years, and two reviews based on systematic literature searches have been published. The first review (Level 2a), ${ }^{30}$ published in 1991, analyzed relevant articles published during the 1980s and revealed that the mortality rate of patients with infected pancreatic necrosis treated by conventional drainage, continuous closed lavage, and open drainage was $42 \%, 18 \%$, and $21 \%$, respectively, and that the outcome of the conventional drainage group was significantly poorer $(P<0.05)$. The other review (Level 2a), ${ }^{31}$ which analyzed articles published in the 1990s, revealed that the mortality rate of the patients with infected pancreatic necrosis treated using the above methods was $23.3 \%, 10.5 \%$, and $28.3 \%$, respectively. When the analysis was limited to articles dealing with severe cases [an average APACHE II (AP-II) score of 17 or more], the mortality rate was $45.8 \%$,

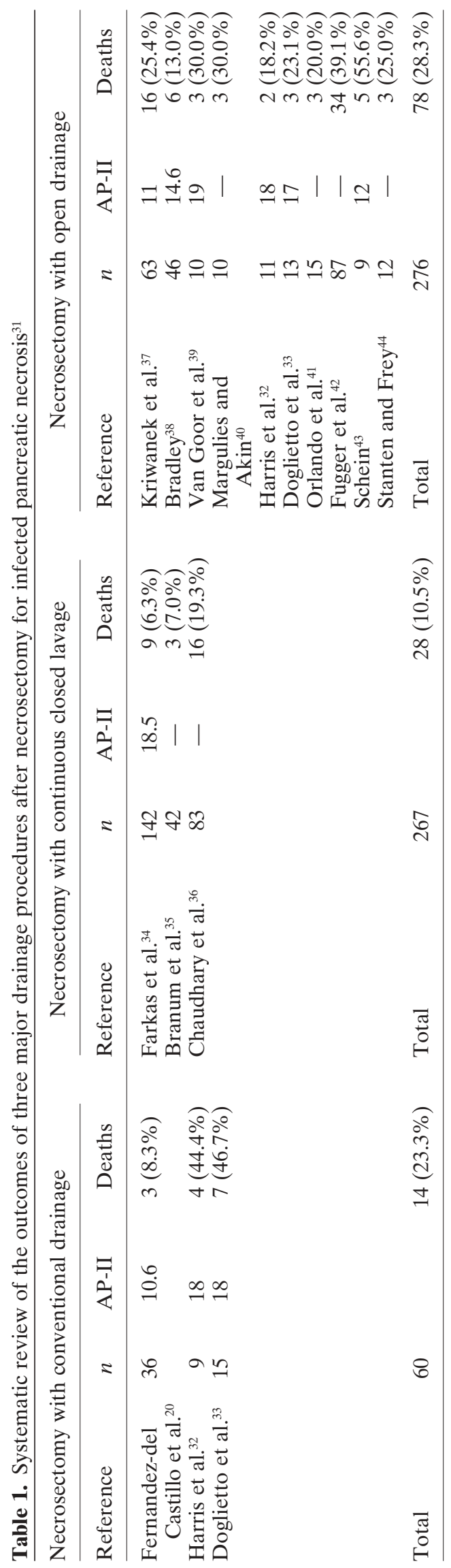


$6.3 \%$, and $23.5 \%$, respectively (Table 1 ). Both reviews show that patients treated by continuous closed lavage had the best outcome.

However, because of extreme inconsistency between the results of two papers ${ }^{34,45}$ on continuous closed lavage, both of which were included in the latter systematic review and were reported by the same author at almost the same time, the reliability of the data is highly questionable. In another paper on continuous closed lavage, ${ }^{35}$ approximately half of the patients underwent repeat laparotomy/debridement 12 or 13 times, and thus the results reported in that paper cannot be considered a pure reflection of the effect of continuous closed lavage.

There is a planned necrosectomy/debridement procedure in which necrosectomy is repeated by temporarily closing the abdominal wound to avoid the excessive invasiveness of open drainage (Level 2c). ${ }^{46} \mathrm{~A}$ recent review compared continuous closed lavage, planned necrosectomy (zipper technique), and open drainage. ${ }^{47}$ The report stated that the mortality rate in necrotizing pancreatitis patients treated by continuous closed lavage, zipper technique, and open drainage was $19 \%$, $24 \%$, and $20.1 \%$, respectively, and that the differences between the groups were not significant. The closed lavage group had a lower incidence of fistula formation (pancreatic fistula and intestinal fistula) and postoperative hemorrhage, but a higher rate of repeat operation, whereas the zipper technique and open drainage were characterized by a higher incidence of fistula formation and postoperative hemorrhage, but a lower rate of repeat operation.

It is difficult to conclude from currently available evidence whether continuous closed lavage or open drainage (or the zipper technique) is better, and in recent years one of these drainage techniques has been chosen freely by surgeons according to the extent of infected necrotic tissue. Continuous closed lavage is chosen when necrotic tissue is localized around the pancreas, and open drainage is recommended if the necrotic area has spread from the root of the mesocolon to the right and/or left paracolic gutter. ${ }^{48}$

Recently, less-invasive procedures have been preferred. Because the pancreas is a retroperitoneal organ, necrosectomy alone by a retroperitoneal approach is performed with simultaneous local lavage (Level 2c). ${ }^{49,50}$ The benefits of this procedure are: (1) peritonitis can be prevented because the abdominal cavity is not entered and infecting organisms are not disseminated into the peritoneal cavity, (2) oral intake can be resumed shortly after the operation, (3) the risk of intestinal fistula formation is low, and (4) the incidence of wound infection and abdominal wall incisional hernia is minimized. The disadvantages are associated with the approach being near the head of the pancreas. It is difficult to reach the posterior surface of the duodenum by a retroperitoneal approach from the right side, and an aggressive procedure involves the risk of massive bleeding as a result of damage to the duodenal wall and portal veins.

Moreover, new less-invasive procedures such as percutaneous necrosectomy (Level 2c) ) $^{51-53}$ and endoscopic transgastric necrosectomy ${ }^{54}$ have been tried and yielded favorable results. Proper evaluation of these new management procedures will require the collection of data from additional cases and follow-up examinations.

\section{Pancreatic abscess}

CQ7. How should pancreatic abscess be managed? CQ8. What is the indication for surgical drainage in pancreatic abscess?

Surgical or percutaneous drainage should be performed for pancreatic abscess (Recommendation B). If the clinical findings of pancreatic abscess are not improved by percutaneous drainage, surgical drainage should be performed immediately (Recommendation A)

Pancreatic abscess is an indication for surgical intervention, just as for infected pancreatic necrosis. Pus collection is the main lesion in most pancreatic abscess patients, and it has been recently reported (Level $3 b)^{55,56}$ that $78 \%-86 \%$ of patients can be managed by percutaneous drainage alone. If a safe puncture route is assured by imaging guidance, this procedure may be the first choice as an aggressive treatment for pancreatic abscess. However, it should be noted that the favorable results reported for this treatment have all been based on retrospective studies, and some of the cases were not pancreatic abscess cases. For example, when severe cases with a Ranson score of 5 or more (Level 2b) $)^{57}$ and cases having multiple abscesses (Level 4) $)^{58}$ were included in the study, the one-stage healing rates of percutaneous drainage declined to $30 \%-47 \%$. When no improvement in clinical findings is observed after percutaneous drainage, surgical drainage should be performed immediately instead of monitoring the clinical course. ${ }^{59}$

\section{Pancreatic pseudocysts}

CQ9. What are the indications for drainage treatment in pancreatic pseudocysts?

Pancreatic pseudocysts that give rise to symptoms and complications or the diameter of which increases should be treated by drainage (Recommendation A)

Generally agreed indications for drainage treatment of pancreatic pseudocysts include (1) accompaniment by 
symptoms, such as abdominal pain; (2) complication by infection or bleeding; (3) increase in size during the observation period; (4) a diameter of $6 \mathrm{~cm}$ or more; and (5) no tendency to decrease in size during at least 6 weeks of observation. There are no reports opposing indications (1) to (3), but because pseudocysts of $6 \mathrm{~cm}$ or larger in diameter may spontaneously resolve after a long follow-up period of 6 weeks or more, (4) and (5), known as " $6 \mathrm{~cm}-6$ week criteria," are not absolute indications for drainage (Levels 3b-4). ${ }^{60,61}$

\section{CQ10. What is the indication for surgical interven- tion in pancreatic pseudocysts?}

Pancreatic pseudocysts that do not tend to improve in response to percutaneous drainage or endoscopic drainage should be managed surgically (Recommendation A)

The drainage procedures for pancreatic pseudocysts include percutaneous, endoscopic, and surgical drainage (mainly cystoenteric anastomosis). Percutaneous drainage, which is the least invasive and has a cure rate of $80 \%-100 \%$, is considered a promising alternative to surgical drainage (Levels 2c-3c). ${ }^{62,63}$ However, some reports have suggested that in a few cases pseudocysts only temporarily resolve after percutaneous drainage (Level 3b), ${ }^{64}$ whereas other reports have indicated that the complete cure rate as a result of surgical drainage is better than that using other drainage procedures (Level 3b). ${ }^{65,66}$ One prospective controlled study (Level $2 b)^{57}$ yielded a one-stage cure rate using percutaneous drainage and surgical drainage of $77 \%(20 / 26)$ and $73 \%$ (18/26), respectively, with no significant differences between them.

Because it has been reported that the average duration of catheterization for percutaneous drainage is 1642 days in cases that respond (Levels $2 c-3 b$ ), ${ }^{62,63}$ surgical drainage, such as cystoenteric anastomosis, should be performed if there is no tendency toward improvement even after this duration. When deciding whether the disease is an indication for percutaneous drainage, it is critical to identify the morphology of the pancreatic duct and its relationship to the pancreatic cyst. Percutaneous drainage has been found to be effective in cases in which the pancreatic duct has normal morphology and in which the pancreatic duct is stenosed but does not communicate with the cyst. ${ }^{67}$ There is a report ${ }^{68}$ that percutaneous drainage is often ineffective for pancreatic pseudocysts complicated by splenic parenchymal involvement, but that distal pancreatectomy and splenectomy are effective.

Endoscopic management may be indicated in some cases of pancreatic pseudocyst. Transintestinal drainage, such as by transgastric and transduodenal drainage (Level 4), and transpapillary drainage (Level 4), ${ }^{69-71}$ are indicated, but transgastric drainage should be performed only when compression of the intestinal wall by a cyst can be confirmed endoscopically. It has been suggested that guidance by endoscopic ultrasonography may enhance the safety of drainage procedures (Level 4). ${ }^{72}$ Transpapillary drainage can be used in cases in which there is communication between the cysts and pancreatic ducts but a transintestinal approach cannot be used. Major complications of endoscopic management include bleeding, infection, and perforation, but there have been no reliable reports comparing effectiveness and safety with that of surgical management.

\section{References}

1. Uhl W, Warshaw A, Imrie C, Bassi C, McKay CJ, Lankish PG, Carter R, et al. IAP guidelines for the surgical management of acute pancreatitis. Pancreatology 2002;2:565-73.

2. Bradley EL III. Guiding the reluctant. A primer on guidelines in general and pancreatitis in particular. Pancreatology 2003;3:13943.

3. Nathens AB, Curtis JR, Beale RJ, Cook DJ, Moreno RP, Romand JA, et al. Management of the critically ill patient with severe acute pancreatitis. Crit Care Med 2004;32:2524-36.

4. Mayumi T, Ura H, Arata S, Kitamura N, Kiriyama I, Shibuya K, et al. Evidence-based clinical guidelines for acute pancreatitis: proposal. J Hepatobiliary Pancreat Surg 2002;9:413-22.

5. Werner J, Uhl W, Hartwig W, Hackert T, Muller C, Strobel O, Buchler MW, et al. Modern phase-specific management of acute pancreatitis. Dig Dis 2003;21:38-45.

6. Karimgani I, Porter KA, Langevin RE, Banks PA. Prognostic factors in sterile pancreatic necrosis. Gastroenterology 1992;103:1636-40. (Prognosis level 4)

7. Widdison AL, Karanjia ND. Pancreatic infection complicating acute pancreatitis. Br J Surg 1993;80:148-54. (Prognosis level 4)

8. Allardyce DB. Incidence of necrotizing pancreatitis and factors related to mortality. Am J Surg 1987;154:295-9. (Prognosis level 4)

9. Bradley EL III, Allen K. A prospective longitudinal study of observation versus surgical intervention in the management of necrotizing pancreatitis. Am J Surg 1991;161:19-24. (Prognosis level 2c)

10. Rattner DW, Legermate DA, Lee MJ, Mueller PR, Warshaw AL. Early surgical debridement of symptomatic pancreatic necrosis is beneficial irrespective of infection. Am J Surg 1992;163:105-9. (Prognosis level 4)

11. Banks PA, Gerzof SG, Langevin RE, Silverman SG, Sica GT, Hughes MD. CT-guided aspiration of suspected pancreatic infection: bacteriology and clinical outcome. Int $\mathrm{J}$ Pancreatol 1995;18:265-70. (Diagnosis level 2b)

12. Rau B, Pralle U, Mayer JM, Beger HG. Role of ultrasonographically guided fine-needle aspiration cytology in the diagnosis of infected pancreatic necrosis. Br J Surg 1998;85:179-84. (Diagnosis level 2b)

13. McFadden DW, Reber HA. Indications for surgery in severe acute pancreatitis. Int J Pancreatol 1994;15:83-90.

14. Ranson JHC. The current management of acute pancreatitis. Adv Surg 1995;28:93-112.

15. Uomo G, Visconti M, Manes G, Calise F, Laccetti M, Rabitti PG. Nonsurgical treatment of acute necrotizing pancreatitis. Pancreas 1996;12:142-8. (Treatment level 3b)

16. Buchler MW, Gloor B, Muller CA, Friess H, Seiler CA, Uhl W. Acute necrotizing pancreatitis: treatment strategy according to the status of infection. Ann Surg 2000;232:619-26. (Treatment level 2c) 
17. Ashley SW, Perez A, Pierce EA, BS, Brooks DC, Moore FD Jr., Whang EE, et al. Necrotizing pancreatitis. Contemporary analysis of 99 consecutive cases. Ann Surg 2001;234:572-80. (Treatment level 2c)

18. Hartwig W, Werner J, Muller CA, Uhl W, Buchler MW. Surgical management of severe pancreatitis including sterile necrosis. J Hepatobiliary Pancreat Surg 2002;9:429-35. (Treatment level 2c)

19. Rattner DW, Legemate DA, Lee MJ, Muller PR, Warshaw AL. Early surgical debridement of symptomatic pancreatic necrosis is beneficial irrespective of infection. Am J Surg 1992;163:105-9. (Treatment level 3b)

20. Fernandez-del Castillo C, Rattner DW, Makary MA, Mostafavi A, McGrath D, Warshaw AL. Debridement and closed packing for the treatment of necrotizing pancreatitis. Ann Surg 1998;228:676-84. (Treatment level 2c)

21. Beger HG, Buchler M, Bittner R, Block S, Nevalainen T, Roscher R. Necrosectomy and postoperative local lavage in necrotizing pancreatitis. Br J Surg 1988;75:207-12. (Treatment level 2c)

22. Foitzik T, Klar E, Buhr HJ, Herfarth C. Improved survival in acute necrotizing pancreatitis despite limiting the indications for surgical debridement. Eur J Surg 1995;161:187-92. (Treatment level 2c)

23. Buchler P, Reber HA. Surgical approach in patients with acute pancreatitis. Is infected or sterile necrosis an indication - in whom should this be done, when, and why? Gastroenterol Clin North Am 1999;28:661-71.

24. Hartwig W, Maksan SM, Foitzik T, Schmidt J, Herfarth C, Klar E. Reduction in mortality with delayed surgical therapy of severe pancreatitis. J Gastrointest Surg 2002;6:481-7. (Treatment level 3b)

25. Mier J, Leon EL, Castillo A, Robledo F, Blanco R. Early versus late necrosectomy in severe necrotizing pancreatitis. Am J Surg 1997;173:71-5. (Treatment level 2b)

26. King NK, Siriwardena AK. European survey of surgical strategies for the management of severe acute pancreatitis. Am J Gastroenterol 2004;99:719-28.

27. Kivilaakso E, Lempinen M, Makelainen A, Nikki P, Schroder T. Pancreatic resection versus peritoneal lavation for acute fulminant pancreatitis. A randomized prospective study. Ann Surg 1984;199:426-31. (Treatment level 1b)

28. Schroder T, Sainio V, Kivisaari L, Puolakkainen P, Kivilaakso E, Lempinen M. Pancreatic resection versus peritoneal lavage in acute necrotizing pancreatitis. A prospective randomized trial. Ann Surg 1991;214:663-6. (Treatment level 2b)

29. Bradley EL III. Management of infected pancreatic necrosis by open drainage. Ann Surg 1987;206:542-50. (Treatment level 2c)

30. D'Egidio A, Schein M. Surgical strategies in the treatment of pancreatic necrosis and infection. Br J Surg 1991;78:133-7. (Treatment level 2a)

31. Isaji S, Kinai T, Naganuma T, Kawarada Y. Surgical treatment strategy for acute necrotizing pancreatitis (in Japanese). ICU CCU 2000;24:665-72.

32. Harris JA, Jury RP, Catto J, Glover JL. Closed drainage versus open packing of infected pancreatic necrosis. Am Surg 1995;61: 612-7. (Treatment level 3b)

33. Doglietto GB, Gui D, Pacelli F, Brisinda G, Bellantone R, Crucitti $\mathrm{P}$, et al. Open versus closed treatment of secondary pancreatic infections. A review of 42 cases. Arch Surg 1994;129:68993. (Treatment level 3b)

34. Farkas G, Marton J, Mandi Y, Szederkenyi E, Balogh A. Progress in the management and treatment of infected pancreatic necrosis. Scan J Gastroenterol 1998;228:31-7. (Treatment level 3b)

35. Branum G, Galloway J, Hirchowitz W, Fendley M, Hunter J. Pancreatic necrosis: results of necrosectomy, packing, and ultimate closure over drains. Ann Surg 1998;227:870-7. (Treatment level 2c)

36. Chaudhary A, Dhar P, Sachdev A, Agarwal AK. Surgical management of pancreatic necrosis presenting with locoregional complications. Br J Surg 1997;84:965-8. (Treatment level 4)
37. Kriwanek S, Gschwantler M, Beckerhinn P, Armbruster C, Roka $\mathrm{R}$. Complications after surgery for necrotizing pancreatitis: risk factors and prognosis. Eur J Surg 1999;165:952-7. (Treatment level 3b)

38. Bradley EL III. Operative versus nonoperative therapy in necrotizing pancreatitis. Digestion 1999;60(Suppl 1):19-21.

39. Van Goor H, Sluiter WJ, Bleichrodt RP. Early and long-term results of necrosectomy and planned re-exploration for infected pancreatic necrosis. Eur J Surg 1997;163:611-8. (Treatment level 4)

40. Margulies AG, Akin HE. Marsupialization of the pancreas for infected pancreatic necrosis. Am Surg 1997;63:261-5. (Treatment level 4)

41. Orlando R III, Welch JP, Akbari CM, Bloom GP, Macaulay WP. Techniques and complications of open packing of infected pancreatic necrosis. Surg Gynecol Obstet 1993;177:65-71. (Treatment level 2c)

42. Fugger R, Schulz F, Rogy M, Herbst F, Mirza D, Fritsch A. Open approach in pancreatic and infected pancreatic necrosis: laparostomies and preplanned revisions. World J Surg 1991;15: 516-20. (Treatment level 3b)

43. Schein M. Planned reoperations and open management in critical intra-abdominal infections: prospective experience in 52 cases. World J Surg 1991;15:537-45. (Treatment level 2c)

44. Stanten R, Frey CF. Comprehensive management of acute necrotizing pancreatitis and pancreatic abscess. Arch Surg 1990;125: 1269-74. (Treatment level 2c)

45. Farkas G, Marton J, Mandi Y, Szederkenyi E. Surgical strategy and management of infected pancreatic necrosis. Br J Surg 1996; 83:930-3. (Treatment level 3b)

46. Garcia-Sabrido JL, Tallado JM, Christou NV, Polo JR, Valdecantos E. Treatment of severe intra-abdominal sepsis and/ or necrotic foci by an "open-abdomen" approach. Zipper and zipper-mesh techniques. Arch Surg 1988;123:152-6. (Treatment level 2c)

47. Bassi C, Butturini G, Falconi M, Salvia R, Frigeri I, Pederzoli P. Outcome of open necrosectomy in acute pancreatitis. Pancreatology 2003;3:128-32. (Treatment level 2a)

48. Kasperk R, Riesener KP, Schumpelick V. Surgical therapy of severe acute pancreatitis: a flexible approach gives excellent results. Hepatogastroenterology 1999;46:467-71. (Treatment level 4)

49. Van Vyve EL, Reynaert MS, Lengele BG, Pringot JT, Otte JB, Kestens PJ. Retroperitoneal laparostomy: a surgical treatment of pancreatic abscesses after an acute necrotizing pancreatitis. Surgery 1992;111:369-75. (Treatment level 2c)

50. Morise Z, Yamafuji K, Asami A, Takeshima K, Hayashi N, Endo T, et al. Direct retroperitoneal open drainage via a long posterior oblique incision for infected necrotizing pancreatitis: report of three cases. Surg Today 2003;33:315-8. (Treatment level 4)

51. Carter CR, McKay CJ, Imrie CW. Percutaneous necrosectomy and sinus tract endoscopy in the management of infected pancreatic necrosis: an initial experience. Ann Surg 2000;232:175-80. (Treatment level 2c)

52. Connora C, Ghaneha P, Raratya M, Suttona R, Rossoa E, Garveyb CJ, et al. Minimally invasive retroperitoneal pancreatic necrosectomy. Dig Surg 2003;20:270-7. (Treatment level 2c)

53. Pamoukian VN, Gagner M. Laparoscopic necrosectomy for acute necrotizing pancreatitis. J Hepatobiliary Pancreat Surg 2001;8: 221-3.

54. Seifert H, Wehrmann T, Schmitt T, Zeuzem S, Caspary WF. Retroperitoneal endoscopic debridement for infected peripancreatic necrosis. Lancet 2000;356:653-5. (Treatment level 4)

55. Van Sonnenberg E, Wittich GR, Chon KS, D'Agostino HB, Casola G, Easter D, et al. Percutaneous radiologic drainage of pancreatic abscesses. Am J Roentgenol 1997;168:979-84. (Treatment level 3b) 
56. Baril NB, Ralls PW, Wren SM, Selby RR, Radin R, Parekh D, et al. Does an infected peripancreatic fluid collection or abscess mandate operation? Ann Surg 2000;231:361-7. (Treatment level 3b)

57. Lang EK, Paolini RM, Pottmeyer A. The efficacy of palliative and definitive percutaneous versus surgical drainage of pancreatic abscesses and pseudocysts: a prospective study of 85 patients. South Med J 1991;84:55-64. (Treatment level 2b)

58. Lee MJ, Rattner DW, Legemate DA, Saini S, Dawson SL, Hahn $\mathrm{PF}$, et al. Acute complicated pancreatitis: redefining the role of interventional radiology. Radiology 1992;183:171-4. (Treatment level 4)

59. Srikanth G, Sikora SS, Baijal SS, Ayyagiri A, Kumar A, Saxena R, Kapoor VK. Pancreatic abscess: 10 years experience. Aust N Z J Surg 2002;72:881-6. (Treatment level 3b)

60. Yeo CJ, Bastidas JA, Lynch-Nyhan A, Fishman EK, Zinner MJ, Cameron JL. The natural history of pancreatic pseudocysts documented by computed tomography. Surg Gynecol Obstet 1990;170:411-7. (Prognosis level 3b)

61. Vitas GJ, Sarr MG. Selected management of pancreatic pseudocysts: operative versus expectant management. Surgery 1992;111:123-30. (Treatment level 4)

62. D'Egidio A, Schein M. Percutaneous drainage of pancreatic pseudocysts: a prospective study. World J Surg 1992;16:141-5. (Treatment level 2c)

63. Adams DB, Anderson MC. Percutaneous catheter drainage compared with internal drainage in the management of pancreatic pseudocyst. Ann Surg 1992;215:571-6. (Treatment level 3b)

64. Criado E, De Stefano AA, Weiner TM, Jaques PF. Long-term results of percutaneous catheter drainage of pancreatic pseudocysts. Surg Gynecol Obstet 1992;175:293-8. (Treatment level 3b)

65. Heider R, Meyer AA, Galanko JA, Behrns KE. Percutaneous drainage of pancreatic pseudocysts is associated with a higher failure rate than surgical treatment in unselected patients. Ann Surg 1999;229:781-7. (Treatment level 3b)

66. Soliani P, Franzini C, Ziegler S, Del Rio P, Dell'Abate P, Piccolo $\mathrm{D}$, et al. Pancreatic pseudocysts following acute pancreatitis: risk factors influencing therapeutic outcomes. J Pancreas 2004;5:33847. (Treatment level 4)

67. Nealon WH, Walser E. Main pancreatic ductal anatomy can direct choice of modality for treating pancreatic pseudocysts (surgery versus percutaneous drainage). Ann Surg 2002;235:7518. (Treatment level 3b)

68. Heider R, Behrns KE. Pancreatic pseudocysts complicated by splenic parenchymal involvement: results of operative and percutaneous management. Pancreas 2001;23:20-5. (Treatment level 3b)

69. Binmoeller KF, Seifert H, Walter A, Soehendra N. Transpapillary and transmural drainage of pancreatic pseudocysts. Gastrointest Endosc 1995;42:219-24. (Treatment level 4)

70. Barthet M, Sahel J, Bodiou-Bertei C, Bernard JP. Endoscopic transpapillary drainage of pancreatic pseudocysts. Gastrointest Endosc 1995;42:208-13. (Treatment level 4)

71. Vitale GC, Lawhon JC, Larson GM, Harrell DJ, Reed DN Jr, MacLeod S. Endoscopic drainage of the pancreatic pseudocyst. Surgery 1999;126:616-21. (Treatment level 4)

72. Seifert H, Dietrich C, Schmitt T, Caspary W, Wehrmann T. Endoscopic ultrasound-guided one-step transmural drainage of cystic abdominal lesions with a large-channel echo endoscope. Endoscopy 2000;32:255-9. (Treatment level 4) 